\title{
Primary Hyperparathyroidism due to Parathyroid adenoma presenting as recurrent acute pancreatitis
}

\author{
Tarun J George ${ }^{1}$, Pughazhendhi Thangavelu², S Zahir Hussain³ , M P Kumaran ${ }^{4}$, \\ Kini Ratnakar ${ }^{5}$, Alwin James ${ }^{6}$ \\ ${ }^{1}$ Final Year Post Graduate, ${ }^{2}$ Professor, ${ }^{5}$ Assistant Professor, ${ }^{6}$ Post Graduate, Institute of Medical Gastroenterology, \\ Madras Medical College, ${ }^{3}$ Professor, ${ }^{4}$ Assistant Professor, Department of Endocrine Surgery, Madras Medical College, \\ Chennai, Tamil Nadu, India
}

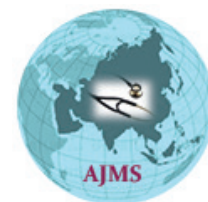

\section{A B S T R A C T}

Primary hyperparathyroidism (PHPT) due to parathyroid adenoma presenting as recurrent acute pancreatitis is a rare entity. A 17-year-old male presented with recurrent attacks of pancreatitis and was found to have elevated serum calcium and Parathyroid hormone levels, $11.9 \mathrm{mg} / \mathrm{dL}(8.5-10.2 \mathrm{mg} / \mathrm{dL})$ and $396 \mathrm{pg} / \mathrm{ml}(10-65 \mathrm{pg} / \mathrm{ml})$ respectively. USG neck showed a $1.1 \times 0.9 \mathrm{~cm}$ hypoechoic nodule in the superior aspect of left thyroid lobe. Parathyroid scintigraphy findings were consistent with parathyroid adenoma. After recovery of pancreatitis, surgical excision of the adenoma was done and the histopathological findings confirmed parathyroid adenoma. There were no further recurrence of pancreatitis following the excision.

Key words: Pancreatitis, Recurrent acute pancreatitis hyperparathyroidism, Parathyroid adenoma, Hypercalcemia

\section{INTRODUCTION}

Recurrent acute pancreatitis (RAP) can be defined as more than two attacks of acute pancreatitis (AP) without features suggestive of chronic pancreatitis. ${ }^{1}$ There are various causes of RAP like biliary microlithiasis, hypertriglyceridemia, pancreas divisum, Sphincter of Oddi dysfunction, parasitic infestation, pancreaticobiliary tumors and hereditary pancreatitis. Hypercalcemia is an uncommon cause of pancreatitis, whether it is due to vitamin $\mathrm{D}$ intoxication, malignancy, hyperparathyroidism, sarcoidosis, total parenteral nutrition or due to high calcium intake. Acute pancreatitis is a rare presentation of primary hyperparathyroidism with incidence rates of 1 and $7 \%{ }^{2}$ Primary hyperparathyroidism due to parathyroid adenoma presenting as Idiopathic recurrent acute pancreatitis (IRAP) is very rare. We report a case of IRAP in association with primary hyperparathyroidism (PHPT) with hypercalcemia due to parathyroid adenoma in a young male with no history of ethanol abuse or gallstone disease.

\section{CASE REPORT}

A 17-year-old male presented with severe abdominal pain and vomiting consistent with acute pancreatitis. This was confirmed with CT abdomen showing bulky pancreas with serum amylase and lipase elevations of $947 \mathrm{U} / \mathrm{L}$ (normal 23-140U/L) and $7947 \mathrm{U} / \mathrm{L}$ (normal up to $140 \mathrm{U} / \mathrm{L}$ ) respectively. The initial biochemical evaluation for etiological workup which included serum triglyceride level-148mg/dL (150-199mg/dL) and serum calcium$10.1 \mathrm{mg} / \mathrm{dL}(8.4-10.4 \mathrm{mg} / \mathrm{dL})$ was normal. There was no history of ethanol abuse, dyslipidemia or medication intake prior to onset of symptoms. Patient was treated with intravenous fluids, proton pump inhibitors and analgesics after which he recovered and was discharged. Over the next 3 months, patient had recurrent attacks of pancreatitis and was evaluated with an MRI abdomen showing bulky pancreas and GB sludge. Biliary pancreatitis was thought of and patient underwent laparoscopic cholecystectomy. Patient was asymptomatic for 1 month 
after which he presented to us with another episode of pancreatitis. Calcium and PTH levels were repeated after the recovery of pancreatitis and was found to be elevated, with $11.9 \mathrm{mg} / \mathrm{dL}$ (Corrected Calcium - $11.7 \mathrm{mg} / \mathrm{dL}$ ) and $396 \mathrm{pg} / \mathrm{ml}(16-65 \mathrm{pg} / \mathrm{ml})$ respectively. Vitamin D levels were $10.9 \mathrm{ng} / \mathrm{ml}(20-50 \mathrm{ng} / \mathrm{ml})$. Ultrasound neck showed a $1.1 \times 0.9 \mathrm{~cm}$ hypoechoic nodule in the superior aspect of the left thyroid lobe. Parathyroid scintigraphy (Figure 1) showed focal area of activity in the superior left lobe consistent with parathyroid adenoma.

One week after complete recovery of pancreatitis, patient underwent surgery. Intra-operative findings showed a parathyroid nodule (Figure 2) suggestive of parathyroid adenoma for which excision was done.

Histopathology (Figure 3) confirmed the findings of parathyroid adenoma. In view of PHPT in this young individual, work-up for MEN syndrome was done which turned out to be negative. On follow up, patient did not have any further recurrence of pancreatitis.

\section{DISCUSSION}

The concept of pancreatitis as a feature of PHPT popularized after the writing of Cope et al in the Annals of Surgery in 1957. ${ }^{3}$ However not all patients with PHPT are prone to develop pancreatitis. Shearer et al showed in their case series of 880 patients with PHPT, acute pancreatitis was documented in only $0.23 \%{ }^{4}$ Bess et al from Mayo clinic did a retrospective analysis of 1153 patients with proven PHPT in which $17(1.5 \%)$ patients developed acute pancreatitis. ${ }^{5}$ The drawback in both these studies were majority of patients were asymptomatic PHPT or with mild hypercalcemia associated PHPT. Carneille et al retrospectively analyzed 1435 patients operated for PHPT, out of which 1224 patients were histo-pathologically proven and cured of PHPT with 211 patients having renal PHPT. $^{6}$ The incidence of pancreatitis was $3.2 \%$ (40 patients) with all patients having significantly higher calcium levels compared to those that did not develop pancreatitis. There was no episode of pancreatitis in patients with renal PHPT with low serum calcium and high PTH levels. ${ }^{6}$ According Kelly et al and Carneille et al, moderate to severe levels of hypercalcemia were more prone to develop pancreatitis than those with normocalcemic or mildly elevated calcium level in the setting of PHPT. ${ }^{6,7}$ This was further supported by SitgesSera who have shown the association of hypercalcemia due to non-hyperparathyroid causes like calcium infusion, myeloma, hyperthyroidism etc with pancreatitis. ${ }^{8}$ The pathophysiology of acute pancreatitis in the setting of

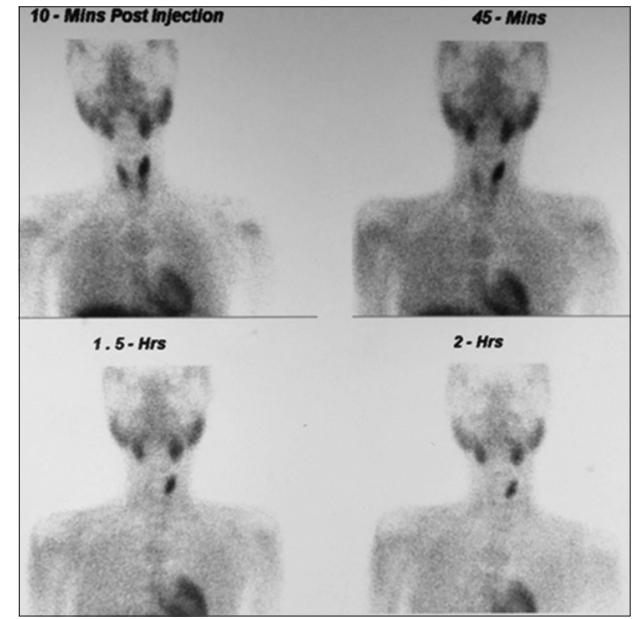

Figure 1: Technetium-99m Sestamibi scan shows an area of tracer retention close to left upper pole of thyroid gland

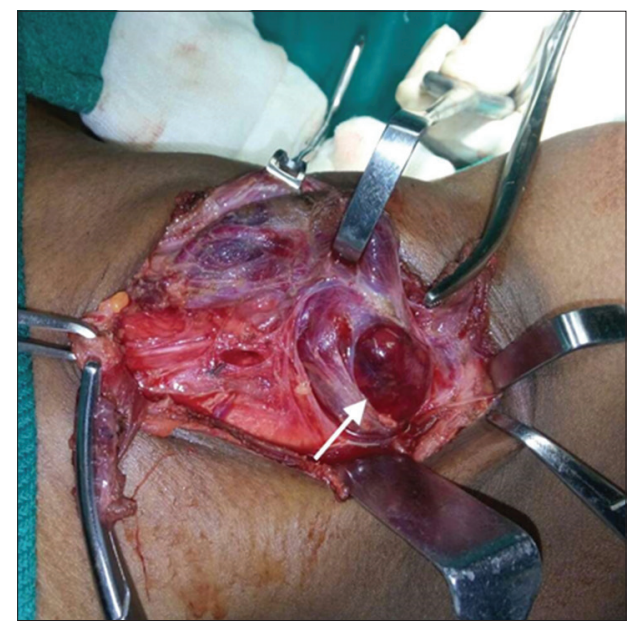

Figure 2: Operative photograph showing the left superior parathyroid adenoma, indicated by white arrow mark

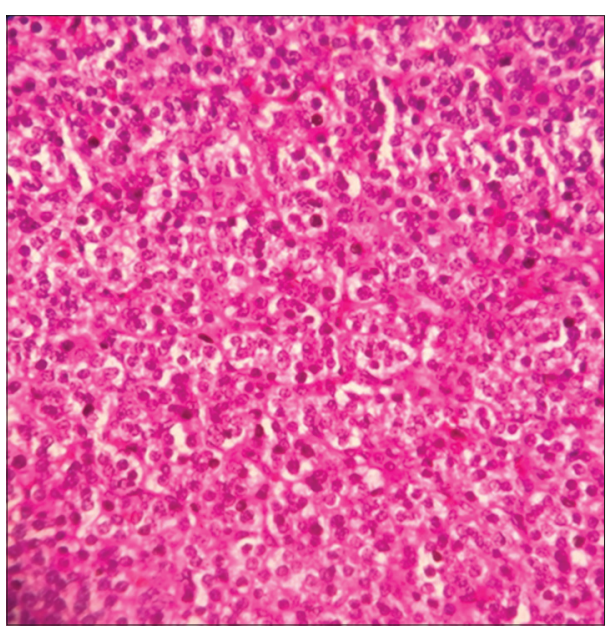

Figure 3: 100x view of parathyroid parenchyma with neoplasm composed of lobules and clusters of polyhedral cells with clear cytoplasm and vesicular nuclei interspersed with congested blood vessel and foci of hemorrhage, findings consistent with parathyroid adenoma 
hypercalcemia has been suggested due to elevated calcium in pancreatic juice resulting inappropriate activation of intra-pancreatic trypsinogen to trypsin causing pancreatitis. Genetic defects like CFTR (cystic fibrosis transmembrane conductance regulator) and SPINK 1 (serine protease inhibitor Kazal Type 1) genes and pancreatic calculus formation due to hypercalcemia has been suggested as the other contributory mechanism of pancreatitis in the setting of hypercalcemia. The diagnosis of hypercalcemia induced pancreatitis can be delayed if calcium levels are done during the episode of pancreatitis, as the calcium levels would be low during the attack. ${ }^{3,10,11}$ Hence the presence of a normal or high serum calcium should prompt a repeat evaluation of calcium and parathyroid hormone levels after the recovery of pancreatitis to rule out primary hyperparathyroidism (PHPT) or an underlying malignancy. Ultrasonography or Technetium-99m Sestamibi scan is useful in localization of the parathyroid glands when planning for surgical treatment. ${ }^{12}$ In our case the presence of hypercalcemia led us to diagnose this patient with primary hyperparathyroidism due to parathyroid adenoma. The improvement in the patient's symptoms and absence of recurrence of pancreatitis following parathyroidectomy compels us to believe, hypercalcemia due to PHPT as the cause of pancreatitis in this case.

\section{CONCLUSION}

Acute pancreatitis is a rare presentation of primary hyperparathyroidism due to parathyroid adenoma. Serum calcium and PTH levels should be assessed after the recovery of pancreatitis, especially in cases of recurrent acute pancreatitis. Parathyroidectomy can resolve PHPT and prevent further recurrence of pancreatitis.

\section{REFERENCES}

1. Kedia S, Dhingra R and Garg PK. Recurrent acute pancreatitis: an approach to diagnosis and management. Tropical Gastroenterology 2013;34(3):123-135.

2. Valenzuela JE, Segura EB, Torres AS and Alvarez FB. Revista Espanola de Enfermedades Digestivas (Madrid) 2009; 101:65-69.

3. Cope O, Culver PJ, Mixter CG and Nardi GL. Pancreatitis, A Diagnostic Clue to Hyperparathyroidism. Annals of Surgery 1957;(145):857-863.

4. Shearer MG and Imrie CW. Parathyroid hormone levels, hyperparathyroidism and acute pancreatitis. British Journal of Surgery 1986;(73):282-284.

5. Bess MA, Edis AJ and Heerden JAV. Hyperparathyroidism and Pancreatitis: Chance or a Causal Association? JAMA 1980; 243(3):246-247.

6. Carnaille B, Oudar C, Pattou F, Combemale F, Rocha J and Proye C. Pancreatitis and Hyperparathyroidism: Forty Cases. The Australian and New Zealand journal of surgery Royal Australasian College of Surgeons 1998; 68:117-119.

7. Kelly TR. Primary Hyperparathyroidism: A personal experience with 242 cases. The American Journal of Surgery 1980;140:632-635.

8. Sitges-Serra A, Alonso M, Lecea CD, Gores PF, and Sutherland ER. Pancreatitis and Hyperparathyroidism. British Journal of Surgery 1988;75(2):158-160

9. Frick TW, Fernández-del Castillo $C$, Bimmler D and Warshaw AL. Elevated calcium and activation of trypsinogen in rat pancreatic acini. Gut [Internet]. 1997;41(3):339-343.

10. Felderbauer $P$, Karakas $E$, Fendrich $V$ and Bulut $K$. Pancreatitis risk in primary hyperparathyroidism: relation to mutations in the SPINK1 trypsin inhibitor (N34S) and the cystic fibrosis gene. The American Journal Gastroenterology 2008;103(2):368-374.

11. Choudhuri G, Somani SK, Baba CS and Alexander G. Autoimmune hepatitis in India: profile of an uncommon disease. BMC Gastroenterol 2005;5:27.

12. Haber R, Kim C and Inabnet W. Ultrasonogrphy for preoperative localization of enlarged parathyroid glands in primary hyperparathyroidism: comparison with $99 \mathrm{~m}$ technetium sestamibi scintigraphy. Clin Endocrinol 2002;57:241-249.

\section{Authors Contribution:}

TG - Concept, reviewed the literature, prepared the manuscript and critical revision of manuscript; PT - Helped in the first draft of manuscript and critical revision of manuscript; ZH - Performed the surgery, provided the operative photos, concept, critical revision of manuscript; MPK - Assisted in the surgery and helped in critical revision of manuscript; RK - Concept, reviewed the article; AJ - Assisted in Literature review, and in providing histopathology images.

Source of Support: Nil, Conflict of Interest: None declared. 